\title{
Editorial \\ Open Review: An Invitation to Participate in Tourism and Hospitality
}

\author{
Brian Garrod
}

check for updates

Citation: Garrod, B. Open Review: An Invitation to Participate in Tourism and Hospitality. Tour. Hosp. 2022, 3, 161-163. https://doi.org/ 10.3390/tourhosp3010012

Received: 30 January 2022 Accepted: 2 February 2022 Published: 7 February 2022

Publisher's Note: MDPI stays neutral with regard to jurisdictional claims in published maps and institutional affiliations.

Copyright: (c) 2022 by the author. Licensee MDPI, Basel, Switzerland. This article is an open access article distributed under the terms and conditions of the Creative Commons Attribution (CC BY) license (https:// creativecommons.org/licenses/by/ $4.0 /)$.
School of Management, Bay Campus, Swansea University, Fabian Way, Swansea SA1 8EN, UK; brian.garrod@swansea.ac.uk

Since taking up the post of Editor-in-Chief of Tourism and Hospitality in 2020, it has been a real pleasure for me to see the journal grow in so many ways. The number of submissions we receive is rapidly increasing, and we have been publishing a larger number of articles in each issue. We have added eminent colleagues to both the editorial board and reviewer board. A growing number of colleagues have also joined us as Guest Editors of Special Issues. We are becoming quite a large community now, and I am grateful for the valued inputs of every one of you.

Perhaps the most important development to take place recently, however, is the redesign of our website to enable fully open review. When readers visit our website (https: / / www.mdpi.com/journal/tourismhosp (accessed on 29 January 2022)), they will see two new things: firstly, the inclusion of open reviewer reports beneath an increasing number of articles; and, secondly, the addition of a control panel with five icons on the right-hand side of each article (see Figure 1).

https://doi.org/10.3390/tourhosp1010001

\section{Open the paper through doi}

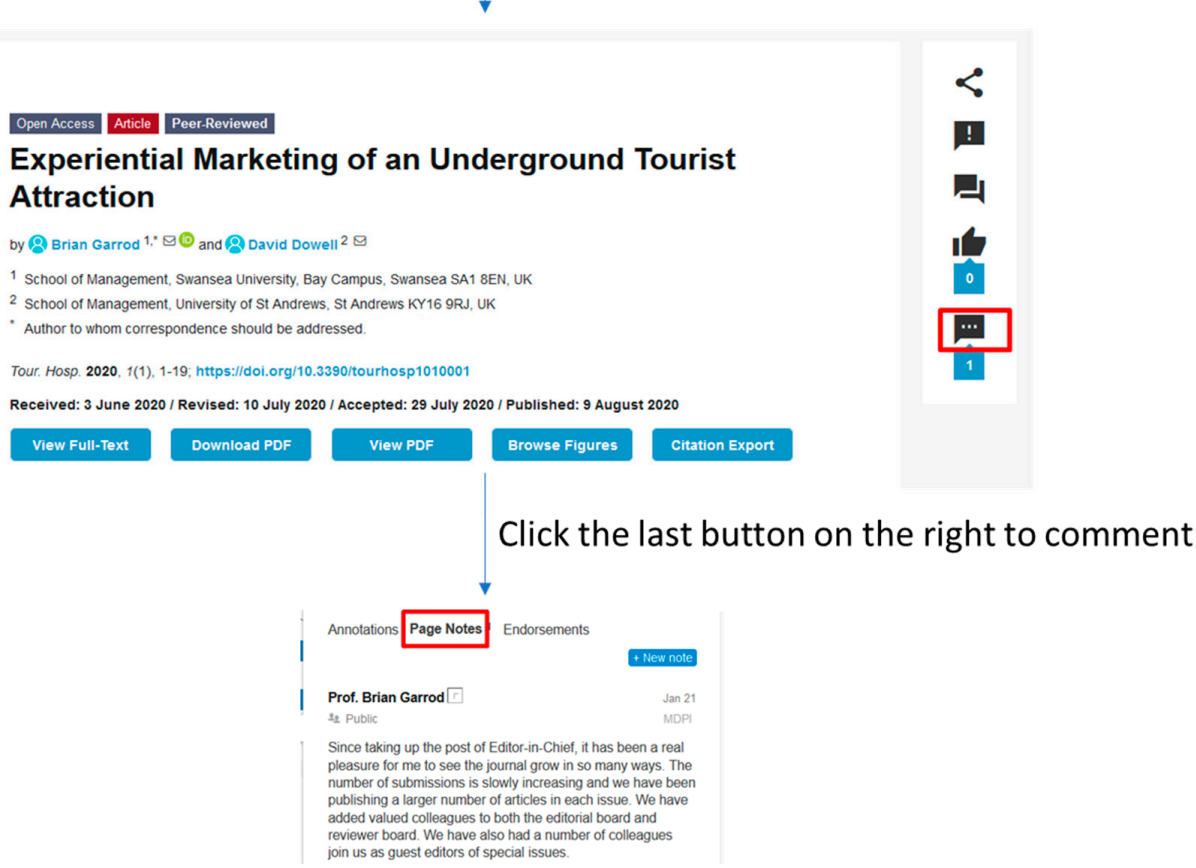

Figure 1. Schematic diagram of how to use the comments facility on the journal website. 
I am particularly pleased that we have been able to add these new features to our platform because they serve as guarantees of the scientific quality of the research we are publishing. The opportunity for readers to read reviewer reports is particularly important because it demonstrates that the article has been through a rigorous review and revision process. I would, therefore, like to encourage authors to opt for the reviewer reports to be published along with their article. I would also like to encourage reviewers to choose to add their name to the published review report. This will mean that the reviewer's name is associated with the review, so that they get full credit for the hard work they have put into it, as such a task requires a lot of time and effort and is performed voluntarily as service to the academic community.

Open access makes the review process more robust by opening it up to scrutiny. This will help to address the criticisms that are still being made about open-access journals with article processing fees. If the critics can see the high standard of reviews we insist upon, perhaps they will allow themselves to be convinced that the new breed of open-access journals is not fundamentally predatory, seeking to publish any paper that is submitted in order to generate profit from it, but strives instead to publish work of a high scientific standard.

This leads on to the next new development, which is the control panel on the righthand side over every article. This makes it possible for anyone to make comments on the articles we publish and, of course, on any open reviews published alongside them. If readers feel that any of the articles we have published are not of an appropriate scientific standard, or if they feel that any of the open reviews published alongside them are not robust, they can now 'call us out'.

I would, therefore, like to invite readers to use this comment function. This can be done by clicking on the bottom icon in the control panel (the one with the three dots). Once signed in, you can add comments of up to 2000 characters, but if this is not enough, please do feel free to continue with a second comment. The authors of the article can then reply to these comments, if they want to, and the comments and replies will appear side by side.

If readers believe that there is a fundamental flaw in an article, they are still, of course, welcome to contribute a traditional comment paper (https:/ / www.mdpi.com/journal/ tourismhosp/instructions (accessed on 29 January 2022)). These are short (2000-2500 word) articles that can be used to raise specific concerns about the scientific credibility of the content of an article. This is another way of 'calling out' the journal if a reader feels we are publishing poor-quality articles. The authors of an article that is the subject of a comment paper will have right to reply, in a 'reply' of similar length.

The comment function can also be used for making brief observations about the article that are not necessarily critical of it. Readers should feel free to use the annotation function, which enables comments to be located at a relevant place in the article, be it a section of text, a table, a figure, or an item in the reference list. Readers may wish, for example, to add an annotation that provides an update on something that is mentioned in the article, or they may wish to provide a link to more recent work on the topic covered by the article. Authors are, of course, very welcome to do the same.

There is also the option for readers to endorse an article if they think it is an important and exemplary piece of work. This can be done by clicking on the 'thumbs up' item, which is second from bottom on the control panel.

This new functionality in our website provides a guarantee of our intention to publish only scientifically correct, academically important research. I would, therefore, like to take this opportunity to challenge the critics of open-access publishing to 'put their money where their mouth is'. Please feel free to call out bad practice. Rather than to dash off a message on a social media platform, you could take the time to prepare a well-reasoned comment. I welcome this as Editor-in-Chief as it keeps everybody, myself included, focused on maintaining the standards we claim we keep to. If we all make use of the opportunities presented to us by open review, article authors will be encouraged to ensure they are submitting scientifically excellent work to begin with, while reviewers will be sure to take the time and effort to produce the best possible reviews. That will mean that I, as Editor, 
can be sure that I select only research that is fit for publication and I can then reject the rest. I call upon readers, including both critics and supporters of the 'paid' open access publishing model alike, to keep us on the straight and narrow.

I would like to conclude this editorial by pointing out the icon at the top of the control panel (the three dots joined by two lines). This is the share icon, which allows readers to share the URL of the article by email, Twitter, LinkedIn, Facebook, Wechat, Reddit, and Mendeley. If you read an article you think is important for others to know about, please feel free to share it around your network. If you see one that you think is of poor quality, please do the same. That is what open access is for and openness can only be a good thing. I believe that the future of academic publishing is an interactive one and I am pleased to say that Tourism and Hospitality is ready for an exciting and successful future.

Conflicts of Interest: The author declares no conflict of interest. 